\title{
Optimizing Public Private Partnership in Implementation of Railway Transport Projects in Kenya: A Case of the National Standard Gauge Railway
}

\author{
Rose Wanja Kinyua and Mary Nyawira Mwenda
}

\begin{abstract}
All over the world, the growing demand for transport infrastructure is on its high and with it comes overstretched and widened fiscal constraints, leading governments to seek specialized financing cooperation between the public and private sectors, known as Public-PrivatePartnership (PPP). This study sought to investigate the influence of public-private-partnership on implementation of railway transport project: A case of Standard Gauge Railway in Kenya. The objectives of the study were to determine the influence of public-private-partnership's financing and private consortium on implementation of railway transport project. The study was grounded on the Agency and Game theories. The study adopted both descriptive survey and interview research designs. The study's target population was the staff working at Kenya Railways, standard gauge railway consultant, standard gauge railway consultant contractor and PPP Unit, totalling to 100 respondents. The study's sample size was 94 . The study adopted purposive and stratified random sampling techniques. Quantitative data was collected through closed ended questionnaires while qualitative data was collected through interview guides. The quantitative data was coded by Statistical Packages for Social Sciences (SPSS). The statistical tools of analysis used for descriptive data were arithmetic mean and standard deviation, with the variables attaining a composite mean ranging between 3.885 and 4.195 and standard deviation ranging between 0.864 and 0.932 . The statistical tools of analysis used for inferential statistics was Pearson Moment Correlation, with the variables attaining a strong positive correlation ranging between 0.735 and 0.889 . The study concluded that public-private partnership's financing and private consortium influence implementation of railway transport project. The study recommended that governments adopt public-privatepartnership as the way forward to railway projects' implementation and private consortium to have organization cultures that are simple to understand.
\end{abstract}

Index Terms - Implementation, Financing, Private Consortium, Financing, Public Private Partnership, Standard Gauge Railway.

\section{INTRODUCTION}

Developing economies face increasing needs for investments in and expansion of infrastructure development projects so as to achieve economic development objectives [1]. The classic on balance sheet falls short of the investment needs and therefore, there is need for resolution of transport infrastructure and development projects' financing issues [2]. As the gap between the growing demands for transport infrastructure and fiscal constraints constantly widens, public private partnership has become the emerging and preferred financing alternative to conventional financing of infrastructure projects. This special mechanism is a cooperation between public and private parties, thus Public Private Partnership (PPP) scheme. PPP concept, according to [3], is a long-term contract amongst government and private organizations engaged in the planning, funding development, management and maintenance of infrastructure facilities.

The main reasons for PPP agreement are to increase the performance and quality of the public service provision project and boost investments for capital intensive projects. According to [4], this shows that PPPs are instrumental in the implementation of infrastructure projects since they can accelerate a country's development. Transport infrastructure projects' development with private capital through PPP scheme has become a commonly adopted procurement methods of construction facilities in both developed and developing countries [5]. Adopting PPP on implementation of standard gauge railway (SGR) transport projects is sought so as to relieve the government's budgetary pressure and fiscal deficit, rehabilitate ageing or poor infrastructure, the desire to introduce competition and the shortage of domestic experience. The influence of PPP on has also been recorded in countries that choose PPP for innovation and technology and management capacity and stakeholders' engagement.

In PPP on implementation of standard gauge railway projects, public authority signs a contract with the private sector, in the context of a special-purpose vehicle (SPV) subcontracting the funding, design, development, operations and maintenance of entities that are often related to its shareholders [6]. The SPV is a legal entity created for reasons such as isolating the project companies from financial risk through risk transfer, financial engineering, securitization, competitive reasons etc. Networks of linked organizations come together to procure and implement the PPP railway project [7]. In Europe, countries use PPP to gain project advantages through division of responsibilities and risks allocation between the public and private entities [8]. [9] noted that the United Kingdom (UK) is recognized to have the most PPP projects in the world, widely called Private Finance Initiatives (PFI). UK has developed sophisticated legal, institutional, regulatory, and business structures to support the expansion of project procurement.

In Asia, Malaysia and Sri Lanka adopted the PPPs concept to increase state capacity in construction of hard facilities for public sector and lower market monopolies [10]. The PPP models on SGR construction offer prospects for the public sectors by creating value for money through life-cycle costs optimization. PPP schemes encourage governments to focus on public facilities, supporting stakeholders' involvement in the project design and implementation. In Sub-Saharan region, the value of PPP projects has grown from less than USD 0.1 billion in 1995 to over USD 4.9 billion in 2010 [11]. 
Ugandan transport project development has seen the cooperation of PPPs in promoting local economy and improved service quality through incorporated private sectors know how, expertise, capital investments, drawing increasing interest from policy makers, researchers, industry practitioners and international community. This means that PPP standard gauge railway projects are economically viable, enhances knowledge transfer and promotes quality infrastructure development.

According to [12], the Government of Kenya (GOK) is on the path of implementing Vision 2030 goals. The development plan of the country covers the period from 2008 to 2030 in order to turn Kenya from a third world nation into a developed and middle-income region. Vision 2030 will see high quality facilities and services with massive investments in transport infrastructure projects given top priority. Kenyan Government recognizes the fact that external funds are needed to support development goals and meet infrastructure gap through the involvements of the private parties such as PPP arrangements. For the last two decades, Kenya, like other developing countries, started attracting private investment into the country's infrastructure sectors. The SGR construction project is one of the infrastructure development goals identified by GOK as a mega PPP infrastructure project that, once implemented, would propel the country towards achieving regional connectivity, increase the country's gross domestic product and give Kenya a competitive edge in the world's economies.

\section{A. Statement of the Problem}

Due to high and intensive capital nature of railway transport projects and the government's limited financial resources, high risks involved throughout the project design and implementation and institutional capacity gaps the governments have realized that partnerships with private parties has become an alternative to improve and increase provision of infrastructure and regional connectivity [13]. A successful PPP railway should distribute assignments, responsibilities, and risk management in an acceptable manner amongst public and private stakeholders. According to [11] PPP parties are government entities and private partners with technical and financial expertise relevant to particular project priorities.

In 2014, Kenya's government signed a regional protocol with other neighboring countries to develop a seamless railways transport system within the framework of regional connectivity, hence the implementation of Standard Gauge Railway (SGR) projects meant connecting Kenya with East and Central Africa's regions. The project was billed at USD3.6 billion making it the largest post-independence transport project in the country. The fiscal budget allocation for the railway construction was limited. SGR project finance was completed in May of 2014. China's Export and Import Bank (EXIM) extended a debt loan of $90 \%$ of project costs and $10 \%$ being provided by the Kenyan government [14].

According to [14], Kenya was lagging behind in innovation, cutting-edge engineering, expertise, machineries and equipment needed for the construction and implementation of the standard gauge railway project, prompting the government to enter into concession agreement with EXIM Bank for the Design, Build, Finance, Operate and Transfer scheme. It is against this background that the study hoped to determine influence of PPP on implementation of railway transport project

\section{B. Objectives of the Study}

The study's objectives were:

1. To examine the influence of project financing on implementation of SGR project in Nairobi County.

2. To assess the influence of private consortium on implementation of SGR project in Nairobi County.

\section{LITERATURE REVIEW}

Globally, owing to the capital-intensive nature of the sector, the implementation of all transport infrastructure projects starts with fund sourcing [15]. Financing, according to [16], comes from international organizations or the governments in which the infrastructure project will be built. Across Africa the construction of infrastructure is seen as crucial to bridging the current economic gaps in the continent. During project formulation, the stakeholders who are the governments, private investors, the financiers of the hard infrastructure among others, set out a standard plan for implementing the projects, within the constraints of time, scope, quality and cost [3]. A research by [17] on the introduction of government infrastructure programs in Africa found that the private sector stakeholders had invested over USD 174.8 billion dollars for implementation of infrastructure projects in the Sub Saharan region only.

Unlike global scenario, project execution of railway transport infrastructure varies depending on African areas and is driven by funding agencies. Owing to the high capital nature of the rail transport projects, the need to construct new transport infrastructures, rehabilitate old facilities and bridge the infrastructures financing gaps, funding for the project comes from multiple sources including states, multilateral and multinational organizations or PPP corporations [17]. The investing agencies determine how to carry out and execute the hard infrastructure programs. The project's design and execution are determined by the national transport authority of a country from which government funding originates. [18] indicated that multilateral financing partners offered guidelines on implementing infrastructure programs, as was the case when Tunisia borrowed USD \$300 million from the European Investment Bank, intended to upgrade its roads and bridges.

Implementation of standard gauge railway transport in Kenya is supervised by the Ministry of Transport, Infrastructure, Housing and Urban Development, whose main task is to place Kenya as the region's logistics hub by developing a modern and effective transport network for goods and services within the counties and also with other countries in the area, with a focus on rail, water and air transport. The GOK intended to invest an approximate amount of USD 60 trillion to develop infrastructure while relying heavily on PPP schemes to achieve its development target, according to [19], and this is in pursuant of the vision 2030 blueprint. The budget deficit out of that was USD 40 trillion by establishing legal and regulatory structure through the enactment of laws and regulations that facilitate and encourage the creation of PPPs, the government has worked to provide the right atmosphere for implementation of PPPs projects. Kenya has a strong track record of railway projects built using PPPs, including the 2006 Kenya-Uganda Railway Concession and the SGR's Phases 1 and 2A.

[12] noted that standard gauge railway transport infrastructure was crucial in promoting socio, economic 
activities, and sector growth, as an efficient and successful transport system is the mainstay of rapid and sustainable growth in terms of local, national, regional, and international integration, improvement of citizens' standard of life, poverty reduction and trade facilitation. The Ministry is responsible for extensive roads networks, railway systems that link the country's major cities, ports and connects Kenya with Uganda, Tanzania, Democratic Republic of Congo and Rwanda as well as over 15 paved runways airports and airstrips [14]. Its core functions include supervising the delivery of transport and infrastructure services by sectoral agencies, policy direction, performance monitoring, assessment, and improvement of the regulatory framework, as well as coordination of activities conducted by the ministry's parastatals or authorities. According to [15], the primacy of infrastructure growth and more so in the railway transport sector, is a key aspect of its strategy to propel the country from a low-to-middle-income economy by 2030.

The Public Private Partnership Unit (PPPU) is established as a special purpose unit within the Government of Kenya's National Treasury (GOK). The PPP unit focuses on acting as the PPP committee's secretariat and technical arm, which is assigned to review and approve the country's PPP projects. Kenya's African Infrastructure Country, Diagnostic (AICD) study estimates that sustained investment of about USD 4 billion per year which is approximately $20 \%$ of GDP over the next decade, would be required to fix the country's infrastructure deficit [19]. To achieve this target, [19] stated that it has been looking for alternatives financing models, aimed at increasing funding even from the private sector, introducing lower-cost technology, while priority being given to investments in infrastructure. PPPs are extremely contentious as financing tools, primarily because of concerns that the government's return on investment is lower compared to the private funder's returns.

Private Partnership Unit to ensure compliance with the 2013 PPP Act [19]. It involves setting up and mandating a PPP project database in Kenya, tracking of liabilities and accounting or budgetary problems relevant to PPP projects. PPP means that public funds are released for other projects and this results in project books being debt-free by purchases off balance sheet. The PPP Act provides a facilitation fund to cover feasibility gap funds, government subsidies, contingent liabilities when crystallizing, support for project planning, ensuring that projects are attractive to the public sector [15]. In projects seeking to provide public services and in order to make the project economically viable, the Government can provide capital subsidy or one-time grant. For other situations, by providing income benefits for a fixed period, including tax cuts or guaranteed taxable income, the Government may finance the project. [20] noted that there are several drivers for PPPs that allow the state sector to maximize the resources and increased efficiency that private institutions can bring to public infrastructure provision of traditionally procured and delivered public sector facilities and services.

A private consortium is usually made by a large group of partners participating in PPP projects and form a company referred to as special purpose vehicle (SPV), to develop, construct, manage and operate the facility over the contract period [6]. For situations where by governments have invested equally in the projects, an equity stake in the SPV is usually but not always allocated [21]. The partnership is typically composed of a contractor, repair company and one or more equity investors [8]. The According to [22], effective implementation of the PPP projects involves a knowledgeable, experienced, financially and technically stable consortium of the private sector. PPP project transaction involves selecting consortium with sound technological solutions for the proposed projects and providing value for money to the end users. [23] noted that the private party should be able to perform contractual PPP positions both technologically and financially. Most PPP ventures need to be a large private partnership for the system to operate.

According to [23], private consortium should have a wealth of project management expertise to help choose the right management style fit for the project. [7] studied critical success factors of PPP implementation in Malaysia. The study's findings established that technological compatibility and complementary multidisciplinary skills of the consortium among the main parties and technological creativity in overcoming the difficulty of the project were determinants of the PPP project's success. Good partnerships are important because related risks are allocated and benefit from the cooperation shared [24]. A research study [23] on successes and failures for PPP projects in the UAE noted that good relationship between the consortium and public party speeded up approvals and project permit and opened discussion channels and rapid clarification of obstacles with the government. Policies for private consortiums should be grounded in multidisciplinary concession competences. [16] concluded that consortium members had to put in expertise with multidisciplinary personnel with broad capabilities in a wide variety of related areas.

\section{A. Theoretical Framework}

The research study was anchored on the Agency and Game Theories.

\section{The Agency Theory}

The agency theory was postulated by Fama in 1980. Agency theory, also referred to as principal-agent theory. It is a management technique by which an entity or agent works on behalf of another agent or entity (the principal) in following the principal's goals and agenda. The agent represents the principal's needs and those of his own within the organization. To achieve the corporate goals of the organization through the agent, a mixture of these interests should be fused, because the agent is in control of the organization's resources. The role of the agent in formulating a strategy and the overall strategic management cannot be underestimated. The organization's philosophy is that proper collaboration should be formed between management and stakeholders working towards common goals.

Numerous scholars have questioned the theory on the agency's organization. [25] rejected the agency theory as it explains the relationship between a principal and his agent only and encourages the agents to cheat and misappropriate the funds. It is a prime illustration of the moral problems which are inherent features of the dynamics of the principalagent. He stated that these were the moral responsibilities that the U.S. Enron Corporation violated that contributed to the owners losing billions. The agents were working for their own agendas. Within PPPs the arrangement of principal agency occurs with the agent is the public partner as the client and the private entity. If the interaction between the two parties is not well defined in the contract documents, then the issues associated with the theory of the organization, such as 
the knowledge asymmetry will usually arise [26]. The consistency of the participants and the relationships between them, and how it is thought out in the beginning, determines PPP's success or failure.

\section{Game Theory}

John von Neumann and John Nash were the main pioneers of game theory in 1944 and later the economist Oskar Morgenstern extensively developed it in the 1950s. Game theory is science of strategy and the optimal decision taking of independent yet competing players within a strategic context. According to [27], it shows the logical processes underpinning the individual's decision-making abilities in a collective manner which contributes to public good. Game theory helps us understand how a group project includes, or eliminates, participation [28]. The optional or mandatory manner in which a construction project is undertaken by the government must either be omitted or integrated. The appeal of the game theory lies in simplified representation of a wide range of conditions within an organization.

Another feature of the theory is that it shows a fair assessment of personal advantages or skills against the common good interest to foster better decision-making at an individual level. This logical calculus relies on different characteristics of a group and the representatives. The game theory can be extended to any system analysis, as it feeds into the related variables. In this study, the selecting PPP's project financing of railway transport infrastructure projects give form to game theory by offering a variety of PPP financing schemes on implementation of the railway infrastructure that promotes return on investments thus value for money.

\section{B. Conceptual Framework for the Study}

Conceptual structure is a graphical mapping of the interrelationship between various variables. The independent variable is a factor that determines the behavior or result of another variable while the dependent variable is a factor that is capable of determining the effect of the independent variable if observed over time and measure.

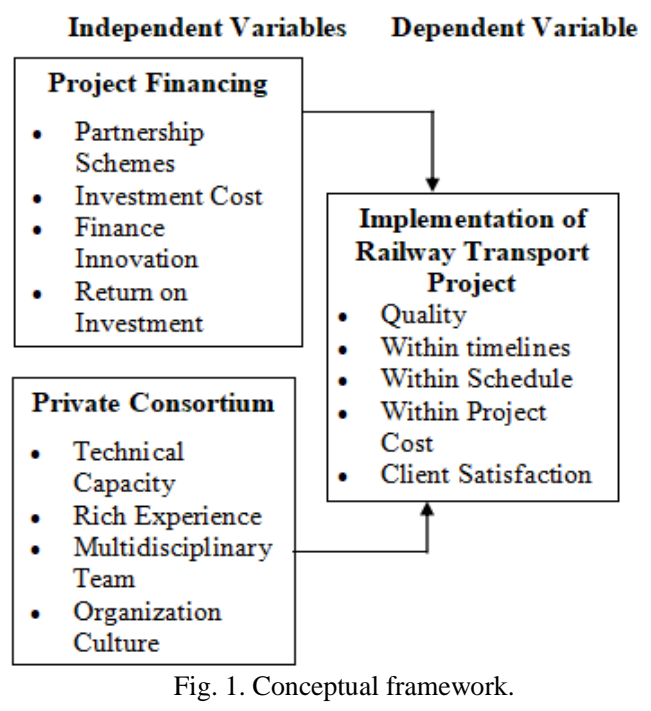

\section{RESEARCH METHODOLOGY}

Cross-sectional survey research design was used in this study. It involved collecting data at a specific point in time and from one or more population, so as to describe the current characteristics of a sample population. The strength of a cross sectional survey is its ability to produce quick, inexpensive, efficient and accurate means of collecting data about the sample population [29]. The researcher collected qualitative data through conducting interviews.

The study's target population were the staff from Kenya Railways, standard gauge railway contractor, standard gauge railway private consultant and the PPP Unit of the National Treasury, totaling to 100 respondents. The sample size indicative of the study population was 94, derived from [30]. Purposive and stratified random sampling techniques were adopted. Closed ended questionnaires were used to collect quantitative data while an interview guide was used to collect qualitative data. Inferential analysis was used to establish the relationship between project financing and private consortium and implementation of railway transport projects.

\section{FINDINGS AND DISCUSSIONS}

Quantitative data was analyzed using arithmetic mean, standard deviation, frequencies, and percentages. Qualitative data obtained from interviews were analyzed using content analysis.

\section{A. General Personal Information of the Respondents}

A total of 94 questionnaires were administered to the respondents. Out of the total, 82 questionnaires were completed and returned, achieving a return rate of $87.23 \%$. A response rate of 50 per cent is satisfactory, 60 per cent is good, 70 per cent is really good, $80 \%$ and above is excellent, [31]. Questionnaire return rate of 87.23 percent was excellent and therefore appropriate for the study's data analysis and reporting.

\section{B. Respondents' Organization}

The research sought to determine the respondents' place of employment. The results are as indicated in Table 1.

\begin{tabular}{ccc}
\multicolumn{2}{c}{ TABLE 1: RESPONDENTS' ORGANIZATION } & \\
\hline Name of the & Frequency & Percentage \\
Organization & 7 & 8.54 \\
PPP Unit & 25 & 30.49 \\
Kenya Railways & 24 & 29.27 \\
SGR Contractor & 26 & 31.71 \\
SGR Consultant & 82 & 100 \\
Total & & \\
\hline
\end{tabular}

According to the findings, $31.71 \%$ of the respondents worked for the standard gauge railway consultant, $30.49 \%$ worked for Kenya Railways, $29.27 \%$ of the respondents worked for the standard gauge railway contractor and $8.54 \%$ worked for PPP Unit. The equal distribution of participants in each stratum ensured more accurate, reliable and unbiased data was collected for the study.

\section{Respondents' Highest Academic Qualification}

The study sought to determine the highest educational qualifications of the respondents. The results are as set out in Table 2.

From the research findings, more than half of the respondents had gone to college, with $64.63 \%$ of the respondents having an undergraduate degree, $19.51 \%$ had a Master's degree, $8.54 \%$ were diploma holders, 3.66 were $\mathrm{PhD}$ degree and 3.66 had studied up to the certificate level. This depicted that the respondents were knowledgeable, understood and filled the questionnaires the way the researcher hoped for. 
TABLE 2: RESPONDENTS' HIGHEST ACADEMIC QUALIFICATION

\begin{tabular}{ccc}
\hline $\begin{array}{c}\text { Highest Academic } \\
\text { Qualification }\end{array}$ & Frequency & Percentage \\
\hline PhD & 3 & 3.66 \\
Masters & 16 & 19.51 \\
Undergraduate & 53 & 64.63 \\
Diploma & 7 & 8.54 \\
Certificate & 3 & 3.66 \\
Total & 82 & 100 \\
\hline
\end{tabular}

\section{Respondents' Years of Service in the Organization}

The research assessed the time period the respondents had served within their organization.

The results are as set out in Appendix 1.

From the study findings, $36.56 \%$ of the respondents had 6 to 10 years of work service in their organization, $31.71 \%$ had 1 to 5 years of work service, $21.95 \%$ had 11 to 15 years of work service, $6.10 \%$ had 16 to 20 years of work service and the least was above 20 years of work service with $3.66 \%$. $68.27 \%$ of the respondents had between 1 to 10 years of experience in their organization, falling within the 6 years of implementation of the standard gauge railway project. This meant that the majority of the respondents had the experience and vast information regarding the implementation of the standard gauge railway project, which contributed to deduction of research opinion and to this research finding a bearing.

\section{E. Respondents' Position in the Organization}

The study sought to establish the respondents' position in their organization.

The findings are presented in Appendix 2.

From the findings, $19.51 \%$ of respondents were contract managers, $15.85 \%$ were project engineers, $14.63 \%$ were civil engineers, $13.41 \%$ were architects, $12.20 \%$ were quantity surveyors, $10.98 \%$ were risk managers, $4.88 \%$ were project developers and $4.88 \%$ were respondents holding any other position in the organizations. This indicated that all the positions targeted for the study were covered and the therefore the findings were adequate to draw conclusions from. The respondents had a technical background in construction and held major roles in the implementation and management of the standard gauge railway project.

\section{F. Analysis of Likert Type of Data}

The study sought to determine the extent to which the respondents agreed with statements relating to financing and private consortium and implementation of railway transport project. The participants were requested to indicate with: Strongly Disagree $=1$; Disagree $=2 ;$ Neutral $=3$; Agree $=4$; Strongly Agree $=5$.

\section{Financing and Implementation of Railway Transport} Project

The results are indicated in Appendix 3.

The results indicated that 51(62.20\%) strongly agreed that PPP is an infrastructure project finance solution, 17(20.73\%) agreed, $3(3.66 \%)$ had a neutral attitude, $6(7.32 \%)$ disagreed and $5(6.10 \%)$ strongly disagreed. The line statement had a mean score of 4.218 and standard deviation of 0.959 which was higher that the composite means of 3.901 and standard deviation of 0.905 , implying that the line influenced implementation of railway transport projects positively.

On the statement that projects face delays in disbursement of funds by financiers, $33(40.24 \%)$ strongly agreed with the statement, $12(14.63 \%)$ agreed, 24(29.27\%) had a neutral attitude, 5(6.10\%) disagreed and 8(9.76\%) strongly disagreed. The line statement had a mean score of 4.066 and standard deviation of 1.001 which is higher than composite mean of 3.901 and standard deviation of 0.905 , implying that the line item influenced implementation of railway transport projects positively.

On the statement that innovative financing approaches in the project are not clear, $46(56.10 \%)$ strongly agreed with the statement, 29(35.37\%) agreed, 5(6.10\%) were neutral, $1(1.22 \%)$ disagreed and $1(1.22 \%)$ strongly disagreed. The line statement had a mean score of 3.988 and standard deviation of 1.207 which is higher than composite mean of 3.901 and standard deviation of 0.905 , implying that the line item influenced implementation of railway transport projects positively.

On the statement that PPP project financing has return on investments, $16(19.51 \%)$ strongly agreed with the statement, 19(23.17\%) agreed, 15(18.29\%) had a neutral attitude $11(13.41 \%)$ disagreed and $21(25.61 \%)$ strongly disagreed. The line statement had a mean score of 3.925 and standard deviation of 0.932 which is higher than composite mean of 3.901 and standard deviation of 0.905 , implying that the line item influenced implementation of railway transport projects positively.

On the statement that PPP projects are faced by cost over runs, $15(15.29 \%)$ strongly agreed with the statement, 9(10.98\%) agreed, 16(19.51\%) had a neutral attitude, $12(14.63 \%)$ disagreed and 30(36.59\%) strongly disagreed. The line statement had a mean score of 3.912 and standard deviation of 1.022 which is higher than composite mean of 3.901 and standard deviation of 0.905 , implying that the line item influenced implementation of railway transport projects positively.

On the statement that PPP bring together a pool of investments, 68(82.93\%) strongly agreed with the statement, $7(8.54 \%)$ agreed, $2(2.44 \%)$ had a neutral attitude, $1(1.22 \%)$ disagreed and $4(4.88 \%)$ strongly disagreed. The line statement had a mean score of 3.912 and standard deviation of 1.022 which is higher than composite mean of 3.901 and standard deviation of 0.905 , implying that the line item influenced implementation of railway transport projects positively.

On the statement that PPP projects have unrealistic budget allocations, 5(6.10\%) strongly agreed, 12(14.63\%) agreed with the statement, 44(53.66\%) had a neutral attitude, $13(15.85 \%)$ disagreed and $9(10.98 \%)$ strongly disagreed. The line statement had a mean score of 4.363 and standard deviation of 0.948 which is higher than composite mean of 3.901 and standard deviation of 0.905 , implying that the line item influenced implementation of railway transport projects positively.

On the statement that PPP projects have poor funds management, $7(8.54 \%)$ strongly agreed with the statement, 17(20.73\%) agreed, 19(23.17\%) had a neutral attitude, $25(30.49 \%)$ disagreed and $14(17.03 \%)$ strongly disagreed. The line statement had a mean score of 3.594 and standard deviation of 0.770 which is lower than composite mean of 3.901 and standard deviation of 0.905 , implying that the line item influenced implementation of railway transport projects negatively.

An interviewee was asked if public private partnership financing contribute to better infrastructure solutions than an initiative that is wholly public, the response given was: 
"Adopting PPP on implementation of railway transport projects, and in this case, standard gauge railway project, is sought so as to relieve the government's budgetary pressure and fiscal deficit, rehabilitate ageing or poor infrastructure, the desire to introduce competition and curb the shortage of domestic experience, where need be"

The statement echoes the views of [17] that the influence of PPP has been recorded in countries that choose PPP for innovation and technology, financial innovation, its competitive bidding process, management capacity and stakeholders' engagement and management capacity.

2. Private Consortium and Implementation of Railway Transport Project

The results are as indicated in Appendix 4.

The results indicated that $39(47.56 \%)$ strongly agreed that Private consortium brings diverse technical skills, $19(23.17 \%)$ agreed, $4(4.88 \%)$ had a neutral attitude, $16(19.51 \%)$ disagreed and $4(4.88 \%)$ strongly disagreed. The line statement had a mean score of 4.018 and standard deviation of 0.864 which was higher that the composite means of 3.911 and standard deviation of 0.855 , implying that the line influenced implementation of railway transport projects positively.

On the statement that private consortium has the capacity required to manage the challenges, 53(64.64\%) strongly agreed with the statement, $9(10.98 \%)$ agreed, $12(14.63 \%)$ had a neutral attitude, $2(2.44 \%)$ disagreed and 6(7.32\%) strongly disagreed. The line statement had a mean score of 4.101 and standard deviation of 0.883 which is higher than composite mean of 3.911 and standard deviation of 0.855 , implying that the line item influenced implementation of railway transport projects positively.

On the statement that local private consortium lacks project technical capacity, 5(6.10\%) strongly agreed with the statement, $17(20.73 \%)$ agreed, $6(7.32 \%)$ had a neutral attitude, $18(21.95 \%)$ disagreed and 36(43.90\%) strongly disagreed. The line statement had a mean score of 3.757 and standard deviation of 0.717 which is lower than composite mean of 3.911 and standard deviation of 0.855 , implying that the line item influenced implementation of railway transport projects negatively.

On the statement that Private consortium has rich project experience, $42(51.22 \%)$ strongly agreed with the statement, $20(24.39 \%)$ agreed, $13(15.85 \%)$ had a neutral attitude, $4(4.88 \%)$ disagreed and $3(3.66 \%)$ strongly disagreed. The line statement had a mean score of 3.902 and standard deviation of 0.698 which is higher than composite mean of 3.901 and standard deviation of 0.905 , implying that the line item influenced implementation of railway transport projects positively.

On the statement that Private consortium's members are from multiple disciplines, 29(35.37\%) strongly agreed with the statement, $31(37.80 \%)$ agreed, $0(0.00 \%)$ had a neutral attitude, 14(17.03\%) disagreed and 3(3.66\%) strongly disagreed. The line statement had a mean score of 3.962and standard deviation of 0.862 which is higher than composite mean of 3.901 and standard deviation of 0.905 , implying that the line item influenced implementation of railway transport projects positively.

On the statement that private consortium's organization culture is complex, 18(21.95\%) strongly agreed with the statement, $10(12.20 \%)$ agreed, $27(32.93 \%)$ had a neutral attitude, $8(9.76 \%)$ disagreed and $19(23.17 \%)$ strongly disagreed. The line statement had a mean score of 3.872 and standard deviation of 0.799 which is lower than composite mean of 3.911 and standard deviation of 0.855 , implying that the line item influenced implementation of railway transport projects negatively.

On the statement that organization culture is not related to successful projects, $3(3.66 \%)$ strongly agreed with the statement, $6(7.32 \%)$ agreed, $7(8.54 \%)$ were neutral, $23(28.05 \%)$ disagreed and $43(54.44 \%)$ strongly disagreed. The line statement had a mean score of 4.210and standard deviation of 0.929 which is higher than composite mean of 3.911 and standard deviation of 0.855 , implying that the line item influenced implementation of railway transport projects positively.

On the statement that cultural differences create project conflicts, 56(68.29\%) strongly agreed with the statement, $11(13.41 \%)$ agreed, $2(2.44 \%)$ had a neutral attitude, 4(4.88\%) disagreed and 9(10.98\%) strongly disagreed. The line statement had a mean score of 4.192 and standard deviation of 1.201 which is higher than composite mean of 3.911 and standard deviation of 0.855 , implying that the line item influenced implementation of railway transport projects positively.

When asked if standard gauge railway's private consortium brought diverse technical skills and capacity into the project, an interviewee answered:

"SGR private consortium has a wealth of project management expertise with the right management style fit for implementation of the mega project, with massive technical teams that has wide and varying technical skills and experience and enabled the projected to be completed well before the stipulated time"

The findings agree with [7], who established that technological compatibility and complementary multidisciplinary skills of the consortium among the main parties and technological creativity in overcoming the difficulty of the project were determinants of the PPP project's success.

\section{G. Inferential Analysis}

The data on project financing and private consortium were analysed using Pearson Correlation Coefficient and averages for each factor calculated into single variables. Pearson's study of correlation was performed at a confidence interval of $95 \%$ and a 2 -tailed confidence level of $5 \%$ significance. Results are as indicated in the correlation matrix between public private partnership and implementation of railway transport project.

The results indicated that Project Financing had a value of 0.846 and p-value of 0.26 and Private Consortium 0.753 and p-value of 0.28 ; implying there was a strong positive correlation between the variables and implementation of railway transport project.

\section{CONCLUSIONS}

The study concluded that PPP's project financing positively influences implementation of railway transport project. This is through PPP acting as an infrastructure project finance solution that reduces over reliance of the fiscal budget which compete heavily with other government projects. PPP bringing together a pool of investments, PPP projects implemented without experiencing cost over runs and PPP projects having proper funds management. 
The study finding helped to draw conclusion that PPP's private consortium positively influence implementation of railway transport project, because it has the capacity required to manage project challenges, private consortium has rich project experience, private consortium brings diverse technical skills and technical capacity. This helps in projects achieving a faster buy in as well as professionals who are used to traditional procurement methods to quickly merge with emerging financial solutions.

\section{RECOMMENDATIONS}

Based on research findings and conclusions, the study recommends that governments adopt PPP as the way forward to transport infrastructure project implementation since it is an innovative financing mechanism. The financing approaches should however be made clear so as to improve project implementation.

It's recommended that PPP private consortium should be have organization cultures that is simple to be understood and which inspire the project workers to focus towards successful transport projects. This is because the study has shown that an organizational culture is related to successful projects.

\section{ACKNOWLEDGEMENT}

I appreciate the University of Nairobi and the staff for supporting my educational goal. I thank my supervisor, Dr. Mary Nyawira Mwenda for her relentless guidance and constant follow up throughout the study.

I acknowledge the Chairman of Graduate School, Prof. Charles Rambo from whom I have acquired deep knowledge on project finance.

Sincere thanks to four powerful and rare gems: My mum Deborah Wambui, Julian Okello, Dr. Margret Mosse for setting life's bar high.
I appreciate APEC Consortium M.D Eng. James Michugu Karanja, OGW and work supervisor Eng. Misheck Waititu Ndungu for lessons learnt: It's not about being a boss but a leader.

I thank my inner circle Dr. George Gatuha, Dr. Charles Muga and Dr. John Njoroge for life and academic inspirations. You are all an epitome of brilliance.

In my Masters Class, I acknowledge Ashford Gikunda and Jeff Onchera for setting leadership standards high.

I would not have made it without my family, who have believed in me and supported my dreams and choices without a question or hesitation.

Finally, I thank God for empowering and immeasurably gracing me to finish my graduate studies.

\section{APPENDIX}

Appendix 1: Respondents' Years of Service in the Organization

\begin{tabular}{ccc}
\hline No. of Years & Frequency & Percentages \\
\hline 1 - 5 years & 26 & 31.71 \\
6 -10 years & 30 & 36.56 \\
$11-15$ years & 18 & 21.95 \\
16 - 20 years & 5 & 6.10 \\
Above 20 years & 3 & 3.66 \\
Total & 82 & 100 \\
\hline
\end{tabular}

Appendix 2: Respondents' Position in the Organization

\begin{tabular}{ccc}
\hline $\begin{array}{c}\text { Position in the } \\
\text { Organization }\end{array}$ & Frequency & Percentage \\
\hline Project Engineer & 13 & 15.85 \\
Quantity Surveyor & 10 & 12.20 \\
Contract Manager & 16 & 19.51 \\
Risk Manager & 9 & 10.98 \\
Architects & 11 & 13.41 \\
Civil Engineer & 12 & 14.63 \\
Financial advisor & 3 & 3.66 \\
Project Developers & 4 & 4.88 \\
Any Other & 4 & 4.88 \\
Total & 82 & 100 \\
\hline
\end{tabular}

Appendix 3: Financing and Implementation of Railway Transport Project

\begin{tabular}{|c|c|c|c|c|c|c|c|}
\hline Statements & 1 & 2 & 3 & 4 & 5 & Mean & S.D \\
\hline PPP is an infrastructure project finance solution & $5(6.10)$ & $6(7.32)$ & $3(3.66)$ & $17(20.73)$ & $51(62.20)$ & 4.418 & 0.959 \\
\hline Projects face delays in disbursement of funds by financiers & $8(9.76)$ & $5(6.10)$ & $24(29.27)$ & $12(14.63)$ & $33(40.24)$ & 4.066 & 1.001 \\
\hline Innovative financing approaches in the project are not clear & $1(1.22)$ & $1(1.22)$ & $5(6.10)$ & $29(35.37)$ & $46(56.10)$ & 3.988 & 1.207 \\
\hline PPP project financing has return on investments & $21(25.61)$ & $11(13.41)$ & $15(18.29)$ & 19 (23.17) & $16(19.51)$ & 3.925 & 0.932 \\
\hline PPP projects are faced by cost over runs & $30(36.59)$ & $12(14.63)$ & $16(19.51)$ & $9(10.98)$ & $15(15.29)$ & 3.636 & 0.838 \\
\hline PPP bring together a pool of investments & $4(4.88)$ & $1(1.22)$ & $2(2.44)$ & $7(8.54)$ & $68(82.93)$ & 3.912 & 1.022 \\
\hline PPP projects have unrealistic budget allocations & $9(10.98)$ & $13(15.85)$ & $44(53.66)$ & $12(14.63)$ & $5(6.10)$ & 4.363 & 0.948 \\
\hline PPP projects have poor funds management & $14(17.03)$ & $25(30.49)$ & $19(23.17)$ & $17(20.73)$ & $7(8.54)$ & 3.594 & 0.770 \\
\hline Composite Mean and Standard Deviation & & & & & & 3.901 & 0.905 \\
\hline
\end{tabular}

Appendix 4: Private Consortium and Implementation of Railway Transport Project

\begin{tabular}{|c|c|c|c|c|c|c|c|}
\hline Statements & 1 & 2 & 3 & 4 & 5 & Mean & S. D \\
\hline $\begin{array}{l}\text { Private consortium brings diverse technical } \\
\text { skills }\end{array}$ & $4(4.88)$ & $16(19.51)$ & $4(4.88)$ & $19(23.17)$ & $39(47.56)$ & 4.018 & 0.864 \\
\hline $\begin{array}{c}\text { Private consortium has capacity required to } \\
\text { manage the challenges }\end{array}$ & $6(7.32)$ & $2(2.44)$ & $12(14.63)$ & $9(10.98)$ & $53(64.64)$ & 4.101 & 0.883 \\
\hline $\begin{array}{c}\text { Local private consortium lacks project technical } \\
\text { capacity }\end{array}$ & $36(43.90)$ & $18(21.95)$ & $6(7.32)$ & $17(20.73)$ & $5(6.10)$ & 3.757 & 0.717 \\
\hline Private consortium has rich project experience & $3(3.66)$ & $4(4.88)$ & $13(15.85)$ & $20(24.39)$ & $42(51.22)$ & 3.902 & 0.698 \\
\hline $\begin{array}{l}\text { Private consortium's members are from } \\
\text { multiple disciplines }\end{array}$ & $8(9.76)$ & $14(17.03)$ & $0(0.00)$ & $31(37.80)$ & $29(35.37)$ & 3.962 & 0.862 \\
\hline $\begin{array}{l}\text { A private consortium's organization culture is } \\
\text { complex }\end{array}$ & $19(23.17)$ & $8(9.76)$ & $27(32.93)$ & $10(12.20)$ & $18(21.95)$ & 3.872 & 0.799 \\
\hline $\begin{array}{l}\text { Organization culture is not related to successful } \\
\text { projects }\end{array}$ & $43(54.44)$ & $23(28.05)$ & $7(8.54)$ & $6(7.32)$ & $3(3.66)$ & 2.010 & 0.929 \\
\hline $\begin{array}{l}\text { Cultural differences create project conflicts } \\
\text { Composite Mean and Standard Deviation }\end{array}$ & $9(10.98)$ & $4(4.88)$ & $2(2.44)$ & $11(13.41)$ & $56(68.29)$ & $\begin{array}{l}4.192 \\
3.911\end{array}$ & $\begin{array}{l}1.201 \\
0.855\end{array}$ \\
\hline
\end{tabular}




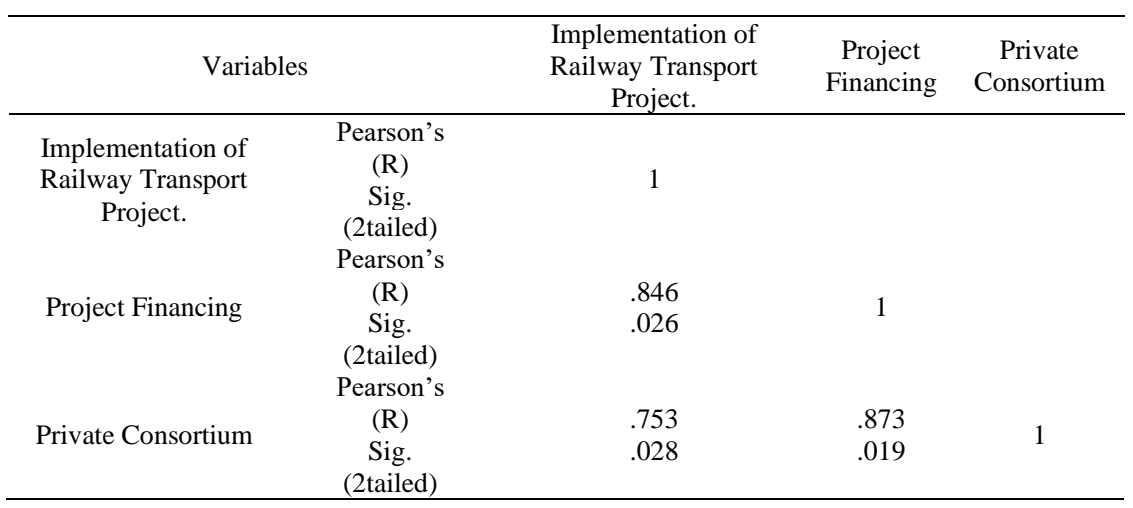

\section{REFERENCES}

[1] J. Klugman., "Human Development Report 2011. Sustainability and Equity: A better future for all," Sustain. Equity A Better Futur. All (November 2, 2011). UNDP-HDRO Hum. Dev. Reports, 2011.

[2] Asian Development Bank, "Public-Private Partnerships," Hand B., 2012.

[3] K. Kimathi., "Unpublished Master thesis on Factors Influencing Implementation of Infrastructure Projects," A Case Road Constr. Proj. Machakos Cty., 2016.

[4] D. Albalate and P. Bel-Piñana., "The effects of public private partnerships on road safety outcomes," Accid. Anal. Prev., vol. 128, pp. 53-64, 2019.

[5] G. Levine,, "Organizations: A Quantum View," Prentice Hall, Englewood Cliffs, NJ, 2000.

[6] J. Barlow., J. Roehrich., and S. Wright., "Europe sees mixed results from public-private partnerships for building and managing health care facilities and services," Health Aff., vol. 32 , no. 1, pp. 146154, 2013.

[7] S. Ismail., "Critical success factors of public private partnership (PPP) implementation in Malaysia," Asia-Pacific J. Bus. Adm., 2013.

[8] A. Panayiotou and F. Medda., "Attracting private sector participation in infrastructure investment: the UK case," Public Money Manag., vol. 34, no. 6, pp. 425-431, 2014.

[9] K. Aaltonen., "Project stakeholder analysis as an environmental interpretation process," Int. J. Proj. Manag., vol. 29, no. 2, pp. 165183, 2011.

[10] R. Jayaseelan and M. Tan., "'PFI-cure for all ills,"” Edge Malaysia, pp. 72-74, 2016.

[11] Asian Development Bank, "Private Sector Assessment Pakistan. Manila," 2010.

[12] Office of Prime Minister, "The Cabinet: Kenyan Ministries," The Government Printer, 2012

[13] OECD, "Recommendation of the council on principles for public governance of public-private partnerships," Paris Organ. Econ. Coop. Dev., 2012

[14] Railway Gazette, "Republic of Kenya," Government Printer, 2014.

[15] The Government of Kenya, "The Ministry of Finance, Nairobi Kenya," Government Printer, 2012.

[16] M. Dada and M. G. Oladokun, "Analysis of critical success subfactors for public-private-partnerships in Nigeria," ALAM CIPTA, Int. J. Sustain. Trop. Des. Res. Pract., vol. 5, no. 2, pp. 13-26, 2012.

[17] L. Bing., A. Akintoye., J. Edwards, and C. Hardcastle, "The allocation of risk in PPP/PFI construction projects in the UK," Int. J. Proj. Manag., vol. 23, no. 1, pp. 25-35, 2005.

[18] World Bank, The World Bank Annual Report 2015. The World Bank, 2015.

[19] The Government of Kenya, "Draft Policy on Aligning the Transport Sector with the Constitution," Government Printer, 2013.

[20] J. Roehrich, M. Lewis, and G. George, "Are public-private partnerships a healthy option? A systematic literature review," Soc. Sci. Med., vol. 113, pp. 110-119, 2014.

[21] M. W. Moszoro and P. Gasiorowski, "Optimal capital structure of public-private partnerships," IMF Work. Pap., pp. 1-13, 2007.

[22] M. Arata., M. Petrangeli., and F. Longo, "Innovative approaches to implement road infrastructure concession through Public-Private Partnership (PPP) initiatives: a case study," Transp. Res. Procedia, vol. 14, pp. 343-352, 2016.

[23] M. Alhashemi., "Critical Success \& Failure Factors for Public Private Partnership Projects in the UAE." The British University in Dubai (BUiD), 2008.

[24] X. Zhang., "Critical success factors for public-private partnerships in infrastructure development," J. Constr. Eng. Manag., vol. 131, no. 1, pp. 3-14, 2005.

[25] J. Laffont and D. Martimort, The theory of incentives: the principal-agent model. Princeton university press, 2009.

[26] A. Hillman and T. Dalziel, "Boards of directors and firm performance: Integrating agency and resource dependence perspectives," Acad. Manag. Rev., vol. 28, no. 3, pp. 383-396, 2003.

[27] H. Kerzner., Project management metrics, KPIs, and dashboards: a guide to measuring and monitoring project performance. John Wiley \& Sons, 2017.

[28] G. Cooke and P. Kothari, Principles of Corporate Finance, 7th Ed. Tat McGraw-Hill, 2001.

[29] D. Cooper., P. Schindler., and J. Sun., "Business research methods," 2003.

[30] R. Krejcie and D. Morgan, "Determining sample size for research activities," Educ. Psychol. Meas., vol. 30, no. 3, pp. 607-610, 1970.

[31] O. Mugenda and G. Mugenda, "Research methods," 2003. 